\title{
Climate, Conflict and Capital: Critical Issues for the MDGs and Beyond 2015
}

\author{
Erik Solheim
}

Abstract As 2015 approaches we need to take stock of how we have delivered on the MDGs. This article argues critical issues for accelerating progress on the MDGs and thinking beyond 2015, on climate, conflict and capital. Each is discussed in turn as to why it matters and what needs to be done.

\section{Introduction}

No doubt there are some great results to the promises to reduce poverty and to increase access to health and education. Not as good as we had hoped, but still great.

However, the substantial decrease in global poverty in the last 20 years as well as much of the progress we have made towards reaching the Millennium Development Goals (MDGs) since 2000, have mainly taken place in Asia. China is by far the largest contributor, but also countries like South Korea, Vietnam and India have had their share. This is largely due to national economic and social development and international trade - not aid.

Still, global aid is largely very successful and aid has played a major role in notable Indicators related to child mortality and education, especially in Africa, but also in other regions.

The bad news is that this promising trend of positive development does not seem to be continuing. In 2009, the number of people living in hunger increased. The rise in the global food prices and the financial crisis have both had devastating effects on the world's poor. In only one year, they have shown us that the great results achieved in the fight against poverty, be it by trade or aid, are very fragile indeed.

\section{And yet we know that bigger challenges lie ahead}

A failure in international efforts to combat climate change could threaten the lives of millions. The majority of today's children who do not attend school or do not have access to health facilities live in areas where there are violent conflicts. And as the financial system is becoming more global, up to ten times as much money disappears out of developing countries as illicit capital flow as development aid coming in. These are three main reasons why we will not reach the MDGs as planned.

After 2015, we must broaden our approach, so that we do not only focus on the MDGs, but on why we do not reach them. The complexity of that answer is huge, but in the end, these three remain: climate, conflict and capital.

\section{Climate}

Climate change reduces human security as a result of drought, flooding, storms, disease and food and water shortages. In addition, the political and institutional capacity to deal with these impacts is weakened. Climate change affects everyone, but the least guilty will be the worst affected: poor people in poor countries.

The fights against poverty and climate change must go hand-in-hand, or we will lose them both. China is increasing its energy supplies by more in two weeks than all of the 47 sub-Saharan countries (with the exception of South Africa) do in a year. A sharp rise in consumption of fossil fuels is, of course, not compatible with limiting climate change. The only way forward is to facilitate a path of development based on new technology. However, in general, clean forms of 
energy are too expensive and access to them is too difficult in comparison with energy from biomass, coal and kerosene. Many poor and middle-income countries find it simpler, quicker and to some extent cheaper to concentrate on oil- and coal-based power supplies rather than on energy efficiency or renewable energy sources such as hydropower or solar and wind power.

Furthermore, emissions from deforestation and forest degradation in developing countries account for about 20 per cent of global greenhouse gas emissions. Conservation of natural forests is thus a cost-effective way of addressing $\mathrm{CO}_{2}$ emissions but the costs of preserving forests cannot be carried by the poor countries alone. Large-scale international transfers of capital will be needed as compensation for reducing deforestation. For example, Norway has pledged US $\$ 2$ billion to the climate and forest initiative.

Mitigation and adaptation measures must be incorporated into development policy. The costs involved in dealing with the problem of climate change will be formidable. There are major challenges involved in mobilising the resources that will be needed to stabilise the climate system. This is not only a matter of willingness and ability. It will also require political and economic creativity and innovation. Ultimately, success or failure will depend on national leadership and effective collaboration between national and international development actors.

Norway has put forward a proposal for a system that could release large-scale funding for adaptation in poor, vulnerable countries. Briefly, the proposal is that a certain proportion of the total quantity of emission allowances should be auctioned internationally. The revenues should be used among other things to fund adaptation measures in the most vulnerable countries and regions. These revenues would vary depending on the size of the emissions trading market and the proportion of the allowances auctioned. But this model could provide a predictable and significant flow of income.

\section{Conflict}

War and armed conflict continue to be among the most serious challenges for development policy. Armed conflict impedes development. Poverty in itself is not a cause of conflict, but poor countries have twice as high a risk of being affected by armed conflict as other countries.

Meeting the MDGs is particularly hard in conflict areas. Even if there are funds available for health and schooling, the risk may be great for the buildings to be destroyed through war actions, as we saw in Gaza last year. No parent will send their children to school if there are mines buried along the road. The absolute majority of the 75 million children out of school live in war-torn areas. In fragile states, ending the armed conflict and peace-building must be priority number one. At the same time, development in the terms of increased income and welfare is a prerequisite for the peace to last.

The pattern of conflict today is different to that a few decades ago. Today, more than nine out of ten armed conflicts are civil wars between groups struggling for secession and independence or fighting for national power and resources. An increasingly large proportion of the world's conflicts are in countries with petroleum resources.

Instability and war have repercussions far beyond the geographical centres of the conflicts themselves. Conflicts have consequences for the whole region. Insurgents cross national borders to acquire weapons and ammunition, and to win support in neighbouring countries. Diamonds, tropical timber, oil and other commodities, as well as illegal drugs, are sources of income that can fuel continued conflict. These goods find a way out of the war-torn country via neighbouring countries. People forced to flee their homes in civil wars tend to seek refuge in other parts of their country or in neighbouring countries in the region.

Conflict can also have more far-reaching, international consequences. The protection of refugees is an international responsibility. Other visible consequences are increased international crime and terrorism. Conflicts in countries such as Afghanistan, Iraq and Somalia have consequences for peaceful European countries.

The recognition of these repercussions means that issues that previously belonged to separate spheres of foreign, security and development policy now must be treated as interlinked. 


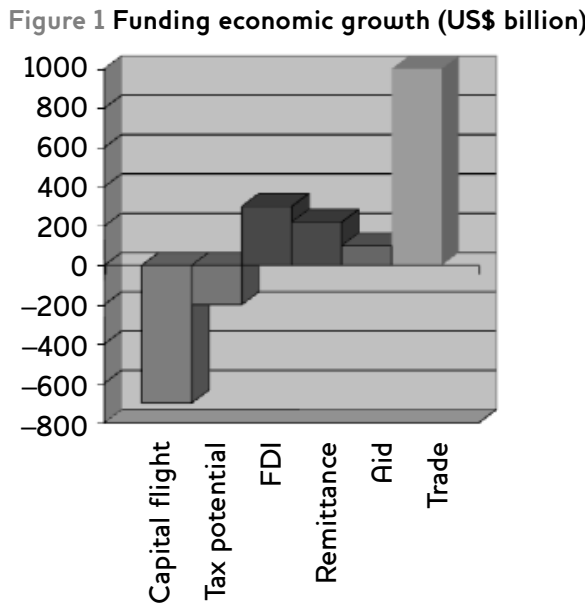

Source Ministry of Foreign Affairs, Norway (2009).

Security is a precondition for political, social and economic development, which is in turn a precondition for lasting peace and stability.

\section{Capital}

Aid is an important source of funding for development. Aid is unique in that it is a source of funding that both donors and recipients have control over, and can thus be administered strategically. It must be used tactically as a development policy tool to mobilise other resources, and to influence national and local development processes.

However, other capital flows - trade, remittances and foreign direct investment (FDI) - have a much larger impact on economic growth and development than aid. The crucially negative impact on income and growth comes from illicit capital flight from developing countries amounting to more than US $\$ 750$ billion a year.

This distribution of capital flows has changed greatly over the past few years. We tend to believe that aid is still the major source of income for the poorer countries. It is true that aid has more than doubled since 1985, but remittances have quadrupled and foreign investments increased ten times!

How this will look in the future, we do not know. The financial crisis, which in a short period of time has resulted in dramatic changes in the economic outlook for both poor and rich countries, demonstrates just how closely interwoven national and global economic
Figure 2 Remittances, aid and FDI (US\$ billion)

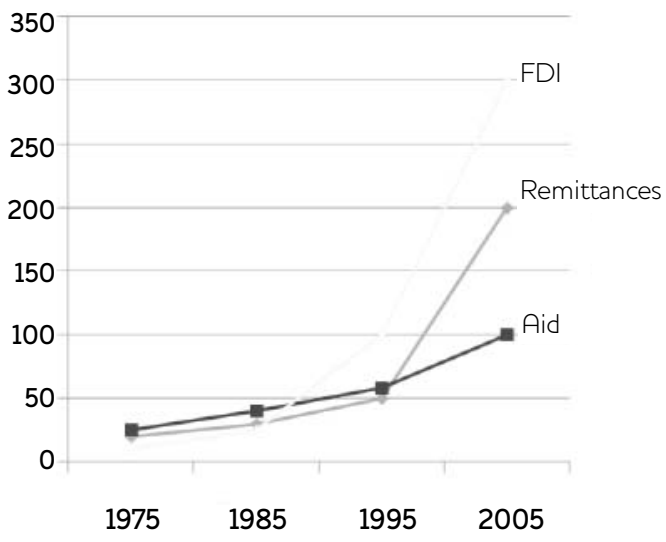

Source Ministry of Foreign Affairs, Norway (2009).

structures have become. The volume of aid, remittances and investments are being challenged. Only the illicit financial flows will no doubt continue to increase.

Illicit financial flows are cross-border financial transactions linked to illegal activities. The proceeds of organised crime such as trafficking in drugs, weapons and human beings account for a substantial proportion of illicit financial flows. Large sums of money also disappear through various types of fraud, corruption, bribery, smuggling and money laundering. However, the largest share of illicit financial flows is related to commercial transactions, often within multinational companies, for the purpose of tax evasion.

These flows are possible mainly because of the tax havens. The fight against poverty is also the fight against tax havens.

Tax havens make economic crime more profitable. Most developing countries lack the resources, expertise and capacity to build up and develop an efficient bureaucracy. The quality of the tax collection system is less well developed than in rich nations. The probability that economic crime will be discovered by the authorities is lower.

More importantly, tax havens damage institutional quality and growth. Potentially the most serious consequences of tax havens are that they can contribute not only to preserving poor institutions but also to weakening them. Tax havens encourage corruption. The lack of 
effective enforcement organisations means that politicians prone to corruption can, to a greater extent, exploit the opportunities which tax havens offer for concealing proceeds from economic crime and rent-seeking. This has led to a wish to weaken the institutions. The financial crisis has provided a unique impetus for the fight against tax havens.

There is an urgent need to strengthen international rules to prevent assets that are illegally appropriated from developing countries from being concealed or laundered in tax havens. We need more knowledge and competence in this field. A broad coalition for politicians, researchers and development activists must prepare for the fight against these incredibly strong economic forces.

\section{Conclusion}

We have come a long way to meet the MDGs, yet not as far as we had hoped. Lack of keeping the aid promises may have contributed to this fact, but it is not the only reason.

\section{Reference}

MFA, Norway (2009) Climate, Conflict and Capital: Norwegian Development Policy Adapting to Change. Report No. 13 (2008-2009) to the Storting, Oslo:
The world has changed dramatically since the turn of the century, when the goals were set. The climate panel made us realise how important climate change is for development, and how interlinked the fights against poverty and climate change are. September 11th 2001 increased our focus on global peace and stability. Afghanistan shows us clearly that there will be no peace without development, and no development without peace. The rise of China (the main source of foreign investment in Africa) as well as other emerging economies has changed the picture of financial flows. Aid is no longer the only important source. And with increased globalisation much is gained, but harmful economic forces also thrive, leading to unbelievably high illicit capital flows from the poor countries.

In five years we shall decide on where to go from the MDGs. The MDGs will always be the important Indicators of development. But the means is no longer aid alone. It is aid combined with a huge global effort to effectively deal with the most critical factors to development: climate, conflict and capital.

Ministry of Foreign Affairs, www.regjeringen.no/pages/2171591/PDFS/ STM200820090013000EN_PDFS.pdf (accessed October 2009) 